\title{
MRI AND BRAIN SPECT FINDINGS IN PATIENTS WITH UNILATERAL TEMPORAL LOBE EPILEPSY AND NORMAL CT SCAN
}

\author{
P.G. CARRILHO, E.M.T. YACUBIAN, A. CUKIERT, L.A. FIORE, C.A. BUCHPIGUEL, C.L. JORGE, \\ H.B. SCAPOLAN, L.A. BACHESCHI, R. MARINO JR
}

\begin{abstract}
SUMMARY - 26 patients with temporal lobe epilepsy clinically documented by several abnormal interictal surface EEGs with typical unitemporal epileptiform activity and a normal CT scan were studied. Interictal ${ }^{99 m}$ TC HMPAO brain SPECT and MRI were performed in all subjects. Abnormalities were shown in $61.5 \%$ of MRI $(n=16)$ and $65.4 \%$ of SPECT $(n=17)$. Hippocampal atrophy associated to a high signal on T2-weighted MRI slices suggesting mesial temporal sclerosis was the main finding ( $n=12 ; 75 \%$ of abnormal MRI). MRI correlated well to surface EEG in $50 \%(n=13)$. There was also a good correlation between MRI and SPECT in $30.7 \%(n=8)$. SPECT and EEG were in agreement in $57.7 \%(n=15)$. MRI, SPECT and EEG were congruent in $26.9 \%(n=7)$. These results support the usefulness of interictal brain SPECT and MRI in detecting lateralized abnormalities in temporal lobe epilepsy. On the other hand, in two cases, interictal SPECT correlated poorly with surface EEG. This functional method should not be used isolately in the detection of temporal lobe foci. MRI is more useful than CT as a neuroimaging technique in temporal lobe epilepsy. It may detect small structural lesions and mesial temporal lobe sclerosis which are not easily seen with traditional CT scanning.
\end{abstract}

KEY WORDS: epilepsy, temporal lobe, CT, MRI, EEG, SPECT.

Achados de ressonância magnética e SPECT cerebral em pacientes com epilepsia unilateral do lobo temporal e com TC de crânio normal

RESUMO - Foram estudados 26 pacientes com epilepsia do lobo temporal clinicamente documentada por vários EEGs com atividade epileptiforme intercrítica e TC de crânio normal. SPECT com ${ }^{99 m}$ TC HMPAO e ressonância magnética (RM) foram realizados em todos os casos. 61.5\% $(n=16)$ das $R M$ e $65.4 \%(n=17)$ dos SPECTs revelaram algum tipo de anormalidade. Atrofia hipocampal, nas imagens enfatizadas em T1 e presença de hipersinal nas imagens enfatizadas em $T 2$, sugerindo esclerose mesial temporal, foram o principal achado ( $n=12 ; 75 \%$ das $R M$ anormais). RM correlacionou-se ao EEG em 50\% ( $n=13)$. Concordância entre RM e SPECT ocorreu em $30.7 \%(n=8)$ e entre SPECT e EEG em $57.7 \%$ ( $n=15$ ). RM, SPECT e EEG foram congruentes em $26.9 \%(n=7)$. Estes resultados refletem o valor do SPECT intercrítico e RM na detecção e lateralização de anormalidades em epilepsia do lobo temporal. Por outro lado, em dois casos, o SPECT correlacionou-se mal com o EEG. Este método funcional não deve ser utilizado isoladamente na detecção de focos temporais. RM é mais útil do que a TC como recurso de neuroimagem na epilepsia do lobo temporal. Ela pode detectar pequenas lesões estruturais e esclerose mesial temporal, não facilmente identificáveis pela $\mathrm{TC}$.

PALAVRAS-CHAVE: epilepsia, lobo temporal, TC, RM, EEG, SPECT.

Single photon emission computed tomography (SPECT) and magnetic resonance imaging (MRI) have recently been shown to be useful as adjunctive methods in the localization of epileptic foci in patients with clinically suspected temporal lobe epilepsy. SPECT studies in epilepsy were first reported in $1983^{3}$ and some authors believe that there is an important role for this method in

Departments of Neurology and Radiology, School of Medicine, University of São Paulo, São Paulo SP Brazil. Aceite: 4-outubro-1993. 
the presurgical evaluation of epileptics. Although some of them ${ }^{1,11}$ claimed that abnormalities could be detected using SPECT in approximately $80 \%$ of patients with focal epilepsy even during the interictal phase, others did not report such good results using this methodology. A low metabolic activity and a low regional cerebral blood flow ( $\mathrm{CCBF}$ ), which parallels this hypometabolism, are usually found within the epileptic focus during the interictal period. It discloses a hypermetabolism and high rCBF during the ictal phase. These findings were well correlated with depth electrode EEG recordings ${ }^{5}$. ${ }^{99 \mathrm{~m}} \mathrm{Tc}$ HMPAO ( ${ }^{99 \mathrm{~m}} \mathrm{TC}$ binding agent hexamethylpropylene amine oxyme) is one of the tracers ${ }^{1,8,11}$ which are currently being used. HMPAO is a lipophilic oxyme that crosses the bloodbrain barrier freely and $85 \%$ of brain uptake occurs on the first passage through the CNS after an intravenous injection. Inside the brain, it forms a hydrophilic compound which returns slowly to the blood. The distribution pattern of HMPAO within the brain reflects $\mathrm{CCBF}$ at the time of the first passage through CNS. Since CBF correlates closely with regional cerebral metabolism, HMPAO SPECT scanning apparently images both ${ }^{1}$. MRI is a neuroimaging method which can show more of the pathological changes in the brain than CT scanning. In temporal lobe epilepsy it has demonstrated tumors, ischemic changes and mesial temporal sclerosis (MTS) not shown by $\mathrm{CT}^{16}$. MTS is an anatomo-pathological concept. This entity can be suspected by the finding of volumetric reduction on $\mathrm{T} 1$ and hyperintense signal on T2-weighted images of the hippocampus as seen in coronal MRI slices. These findings seem to be well correlated to the temporal focus observed on EEG and some authors found temporal lobe atrophy ipsilateral to EEG in $75 \%$ of their patients ${ }^{7}$.

This paper analyses interictal SPECT and MRI findings in patients with unilateral temporal lobe epilepsy with a normal CT scan.

Table 1. Summary of the EEG, SPECT and MRI findings.

\begin{tabular}{|c|c|c|c|c|}
\hline Case & Age & $\mathrm{EEG} / \mathbf{n}$ & SPECT & MRI \\
\hline 1 & 43 & $\mathrm{RT} / 2$ & RT & RT \\
\hline 2 & 22 & LT/4 & LT & LT \\
\hline 3 & 41 & LT/3 & LT & LT \\
\hline 4 & 36 & $\mathrm{RT} / 1$ & NL & NL \\
\hline 5 & 26 & LT/4 & NL & LT \\
\hline 6 & 25 & $\mathrm{RT} / 5$ & RT & NL \\
\hline 7 & 29 & $\mathrm{RT} / 2$ & NL & Gliosis/RT/LT \\
\hline 8 & 63 & $\mathrm{RT} / \mathbf{1}$ & RT & NL \\
\hline 9 & 21 & $\mathrm{RT} / 2$ & RT & NL \\
\hline 10 & 26 & $\mathrm{LT} / 1$ & RT & Small Cyst LT \\
\hline 11 & 59 & $\mathrm{LT} / 2$ & LT & Diffuse Atrophy \\
\hline 12 & 31 & LT $/ 3$ & NL & LT \\
\hline 13 & 26 & $\mathrm{RT} / 3$ & NL & RT \\
\hline 14 & 52 & $\mathrm{LT} / 1$ & NL & Diffuse Gliosis \\
\hline 15 & 62 & LT/4 & RT & NL \\
\hline 16 & 33 & $\mathrm{LT} / 11$ & LT & NL \\
\hline 17 & 41 & LT/5 & LT & Post LT Gliosis \\
\hline 18 & 32 & $\mathrm{RT} / 5$ & NL & RT \\
\hline 19 & 16 & $\mathrm{LT} / 10$ & LT & NL \\
\hline 20 & 30 & $\mathrm{LT} / 10$ & LT & LT \\
\hline 21 & 40 & $\mathrm{RT} / 2$ & $\mathrm{RT}$ & NL \\
\hline 22 & 30 & LT/3 & LT & LT \\
\hline 23 & 22 & $\mathrm{RT} / 11$ & RT & NL \\
\hline 24 & 36 & $\mathrm{RT} / 10$ & RT & RT \\
\hline 25 & 28 & RT/9 & NL & RT \\
\hline 26 & 10 & $\mathrm{LT} / 1$ & NL & NL \\
\hline
\end{tabular}

LT, left temporal MTS; RT, right temporal MTS; NL, normal; EEG/n, number of EEGs performed with epileptic interictal activity.

\section{METHODS}

26 patients were studied ( 15 males; 11 females). Age ranged from 10 to 63 years. All had clinically documented temporal lobe epilepsy and, at least, one abnormal EEG with unitemporal epileptogenic activity and a normal third generation CT scan.

Brain SPECT using ${ }^{99 m}$ TC HMPAO was performed in all subjects during the interictal stage, with images obtained 15 minutes after administration of $30-35 \mathrm{mCi}$ of tracer which was tested before every exam in its labelling efficiency. A rotational gamma camera (Siemens-Orbiter) was used for image acquisition. The slices were reconstructed in a Micro Delta Siemens computer using the Euromenu software and the Butterworth filter without correction for attenuation. The slices were reconstructed in the temporal, frontal and sagittal axes. Transaxial slices with a $6 \mathrm{~mm}$ thickness were reconstructed in the temporal plane. Coronal slices were reconstructed perpendicular to this plane.

MR images were obtained on a $1.5 \mathrm{~T}$ system (Signa; GE Medical Systems, Milwaukee). T1 and T2 images were obtained on coronal, sagittal and axial planes with special emphasis over the temporal lobes.

Visual analysis of both SPECT and MRI results was blindly performed by the neuroradiology team.

\section{RESULTS}

The results of MRI, SPECT and EEG are summarized in Table $1.61 .5 \%(n=16)$ of MRI showed abnormalities and 11 (68.7\% of all abnormal MRI) showed unilateral MTS, defined as a hyperintense signal on T2- 


\section{EEG}

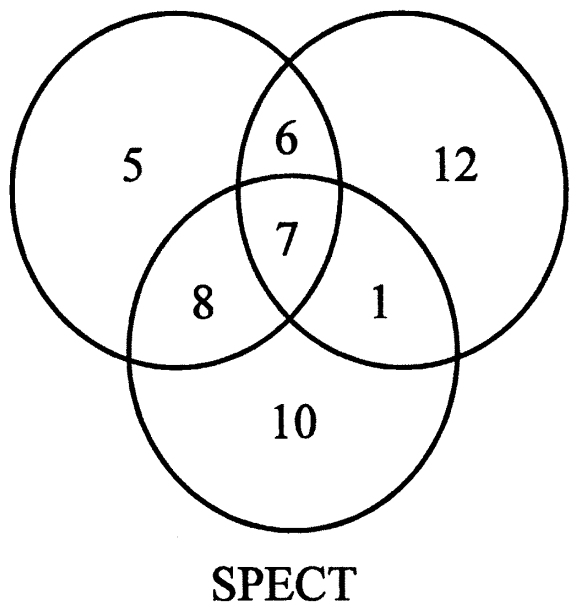

MRI

Fig 1. Venn diagram showing the correlation between EEG, SPECT and MRI findings.

weighted and volumetric reduction on T1-weighted images of mesial structures of the temporal lobe, specially the hippocampus. Other findings, unrelated to MTS were observed in MRI but not on CT ( $n=5)$. In Case 10 a small cyst was seen in the left temporal lobe and it was well correlated to EEG, but not to SPECT. In Case 17 there was an image suggestive of left posterior temporal gliosis which was lateralized as in EEG and SPECT. Cases 7 and 14 showed diffuse gliosis and in Case 7 a bilateral MTS could be seen. Case 11 disclosed global atrophy.

MRI and EEG were in agreement in 13 cases (50\%). In cases with MTS seen in MRI $(n=11), 100 \%$ of the EEGs pointed to the same temporal lobe.

$65.4 \%(n=17)$ of brain SPECTs showed lateralized abnormalities characterized by focal hypoperfusion over one temporal lobe. There was congruence between EEG and SPECT in $57.7 \%$ of cases $(n=15)$. In two cases ( 10 and 15) SPECT results were contralateral to surface EEG findings. A good correlation between MRI and SPECT in $30.7 \%(n=8)$ of the cases was observed.

There was agreement in lateralizing the epileptic foci among SPECT, EEG and MRI in $26.9 \%(n=7)$. Figure 1 shows the relationship between the results obtained using these three methods.

\section{COMMENTS}

SPECT and MRI are tools used in the localization of epileptic foci. Some authors claimed that interictal perfusion deficits correlated well with temporal lobe foci which could be detected using SPECT in approximately $80 \%$ of patients with focal epilepsy. Others were not able to reproduce these results ${ }^{12}$. Interictal SPECT studies may include a number of false positive and negative results, because the precise time course of the perfusion abnormalities is unknown. This might explain conflictant basic and clinical data derived from our study and others ${ }^{4}$.

Ictal and post-ictal SPECTs ${ }^{13,14}$ may be more precise in this respect. PET studies ${ }^{6,10}$ seem to have yielded a higher diagnostic rate but they are more expensive than SPECT.

Our results support the idea that interictal SPECT seems to be an useful adjuvant tool in the study of potential surgical candidates. Lateralization of the SPECT abnormality is in agreement with interictal EEG in about $65 \%$ of cases $^{9}$. Our results showed a slightly smaller rate (57.7\%). 
Some authors propose ${ }^{2}$ that the sensitivity of interictal SPECT can be increased up to $90 \%$ when combined with MRI. In the pre-surgical evaluation of these cases, it does not seem necessary to perform any expensive or invasive investigation. Even when non-congruent, ictal and postictal studies could yield additional data, without the need for invasive EEG methods.

MRI brought new horizons in neurodiagnostics. In temporal lobe epilepsy, it has proven to be sufficiently sensitive to demonstrate MTS. Our data showed that there is a good correlation (100\%) between the finding of a hyperintense signal on T2-weighted and volumetric reduction on T1-weighted images of temporal mesial structures and surface EEG $(n=11)$. On the other hand, some authors ${ }^{16}$ found that increased signal intensity on MRI did not necessarily correlate with the degree of pathological abnormality.

Swartz et al. ${ }^{15}$ showed only $32.5 \%$ of abnormalities on CT scans performed in 37 patients who had undergone temporal lobe surgery. No MTS was observed on CT. MRI was accurate in $60 \%$ of all cases in which mesial temporal sclerosis was identified by histological criteria. Their data also supported the idea that MRI has replaced CT as a structural study in temporal lobe epilepsy. MRI was able to accurately demonstrate a pathological condition which has been closely associated with epileptogenic activity in this type of epilepsy.

Experience with brain SPECT is still increasing. Interictal SPECT seems to be a valuable but not a definitive tool in detecting temporal lobe foci, specially when considering a single study. Only 7 cases out of 26 had an agreement among EEG, SPECT and MRI and $15(57.6 \%)$ had an agreement between SPECT and EEG. On the other hand, in the 17 cases who showed abnormal SPECTs, there was a better relationship with EEG (88\%). This is also true for MRI. Once a lateralized abnormality (MTS) was detected, the congruence with EEG was higher (100\%). Serial studies may improve these results.

\section{REFERENCES}

1. Biersack, HJ, Reichman K, Winkler C. ${ }^{99 m} \mathrm{TC}$ labelled hexamethylpropyleneamine oxime photon emission scans in epilepsy. Lancet 1985, 2:1436-1437.

2. Biersack HJ. Brain SPECT in epilepsy. Are interventional techniques necessary?. Proc Internat Symposium Focal Epilepsy: clinical use of the emission tomography. Paris, 1989.

3. Bonte FJ, Stokely EM, Devous MD, Homan RW. Single photon tomographic determination of rCBF. Am J Neuroradiol 1983, 4:544-546.

4. Duncan R, Patterson J, Hadley DM. Tc-99m HMPAO SPECT in temporal lobe epilepsy. Acta Neurol Scand 1990, 81:287-293.

5. Engel J, Kuhl DE, Phelps ME, Mazziotta JC. Interictal cerebral glucose metabolism in partial epilepsy and its relation to EEG changes. Ann Neurol 1982, 12:510-517.

6. Engel J. The use of PET in epilepsy. Ann Neurol 1984, 25:s86-s104.

7. Jack CR, Cascino G. Temporal lobe volume measurement from MR images: accuracy and left-right asymmetry in normal persons. J Comp Assist Tomogr 1988, 12:21-29.

8. Lassen NA. ${ }^{133} \mathrm{Xe},{ }^{99 \mathrm{~m}} \mathrm{TC}-\mathrm{HMPAO}$ and other tracers for measurement of CBF by SPECT in temporal lobe epilepsy. Proc Internat Symposium Focal Epilepsy: clinical use of functional imaging by means of emission tomography. Paris, 1989.

9. Lassen NA. Concluding remarks. Proc Internat Symposium Focal Epilepsy: clinical use of emission tomography. Paris, 1989.

10. Mazziotta JC, Engel J. The use and impact of PET in epilepsy. Epilepsia 1984, 24:s86-s104.

11. Podreka I, Suess E, Goldemberg G. Initial experience with technetium ${ }^{99 \mathrm{~m} H M P A O}$ brain SPECT. J Nucl Med 1987, 28: 1657-1666.

12. Rowe C, Berkovic S, Austin M, Saling M, Kalnins R, McKay W, Bladin P. Visual and quantitative analysis of interictal SPECT with ${ }^{99}$ TC HMPAO in temporal lobe epilepsy. J Nucl Med 1991, 32:1688-1694.

13. Rowe C, Berkovic S, Austin M, McKay WJ, Bladin PF. Postictal SPECT in epilepsy. Lancet 1989, 1:389-390. 14. Shen W, Lee BI, Park HM, Siddiqui AR, Wellman HN, Markand ON. HIPDM SPECT brain imaging in evaluation of intractable epilepsy for temporal lobectomy. Neurology 1989, 39 (Suppl 1): 132.

15. Swartz BE, Tomiyasu U, Delgado-Escueta AV, Mandelkern M, Khonsari A. Neuroimaging in temporal lobe epilepsy. Test sensitivity and relationships to pathology and postoperative outcome. Epilepsia 1992, 33:624-634.

16. Theodore WH, Katz D, Kufta C, Sato S, Patronas N, Smothers P, Bromfield E. Pathology of temporal lobe foci: correlation with CT, MRI and PET. Neurology 1990, 40:797-803. 